\title{
Pulso ng mga kabataang Irosanon sa darating na halalan
}

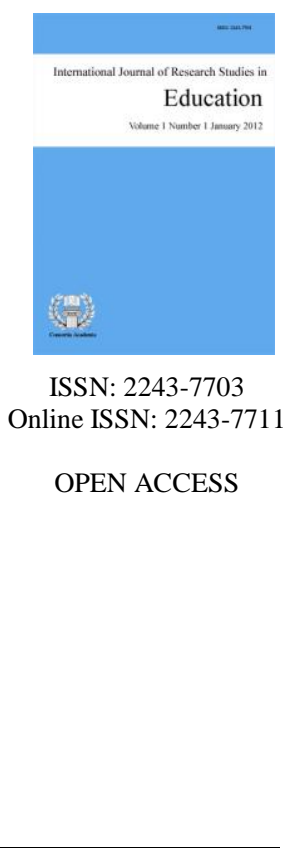

Ranoco, Ma. Zyra B.

Veritas College of Irosin, Philippines (belozyra@gmail.com)

Doritan, Joyce L.

Veritas College of Irosin, Philippines

Fuller, Rhea Mae

Veritas College of Irosin, Philippines

Pamplona, Meccaella

Veritas College of Irosin, Philippines

Gelilio, Eric $\bowtie$

Veritas College of Irosin, Philippines

Sorsogon State University, Philippines

Gallanosa National High School, Philippines (gelilioeric@gmail.com)

\section{Abstract}

This study was conceptualized the perspective of a newbie voters in Veritas College of Irosin particularly the students of BSBA, school year 2021-2022. This research used descriptive analysis design sampling method in gathering all the data from 76 respondents 8 sections of BSBA students. This research used ranking of how they would vote for the upcoming election particularly the students of BSBA to analyze the impacts, factors, and the perspective of the newbie voters. Based on the interpretation and analysis of the data, newbie voters in BSBA students converted the perspective and the aspect of the old voters. According to Rui Antunes the man used the theoretical models of electoral behavior, psychology model of voting behavior and rational choice theory-stressing the continuity and theoretical complementarity between them. It also proposes a reconceptualization of the concept of partisanship in order to integrate all the relevant contributions of the three main models of voting behavior in holistic approach to electoral behavior. According to the study of the election expert's that the election here in the Philippines have the most political dynasty that been taking of some candidates that their target just to have the power not to help the people that make them win the raise.

Keywords: teens (new voters), strategies, innovative strategies, impacts, Irosanon 


\section{Pulso ng mga kabataang Irosanon sa darating na halalan}

\section{Introduksiyon}

Ang kabataan ay ang magiging instrumento ng pagiging marangal ng eleksiyon para sa paraan o hakbang ng pagboto ng mga bagong botante sa darating na halalan 2022. Ang kabataan ay may malawak na responsibilidad ayon sa ating pananaw o magiging resulta ng gaganaping eleksiyon. Ang mga bagong botante o mas kilala bilang bagong rehistro ay may mataas na kredibilidad upang maipakita ang kanilang kakayahan na pumili at maghusga kung sino ang kanilang iboboto. Sila ang nagsisilbing pundasyon ng sistematiko, mabusisi at organisadong pagpili ng karapat-dapat na kandidato.

Alinsunod nga sa Republic Act No. 8189 na lahat ng may kakayahang bumuto ay maaaring bumuto. Ang R.A. No. 8189 ay kilala bilang "The Voters Registration Act of 1996". Ang batas na ito ay nagbibigay ng pangkalahatang karapatan na magparehistro bilang botante, ang pag-aadap nito ay nagpapatuloy na magparehistro, nakatala ang mga hakbang para dito, at ang pagbibigay ng kabayaran upang mabigyan ng awtorisadong pagboto. Nakapaloob dito ang mga hakbang at karapatan ng isang botante na pumili at maghusga ng kandidatong dapat niyang iboto.

Ang panukalang ito ay nakapaloob ang mga bagong botante, at ang mga kandidatong tatakbo sa kanilang napupusuang posisyon. Dahil sa pamamaraang ito naipapakita ang katalinuhan ng isang botante para sa kanyang ganap na pagpili. Nagiging mapili at mapanuri at ito'y bumabase sa rekord ng isang kandidato. Hindi lingid sa kaalaman ng lahat na tanging gampanin ng isang kandidato sa isang eleksiyon ay ang pagboto. Saklaw nito ang iba't ibang larangan ng paraan at pagpili upang higit na malinang ang kakayahan ng bawat kasalukuyang botante sa aspekto ng pagharap sa mga kasalukuyan kaganapan ng lipunan. Ang isang botante ay kumakatawan sa isang masusing pagsusuri ng kaalaman sa pagpili, abilidad, kakayahan sa pagkatao ng isang indibidwal.

Sa patuloy na pagbabago ng sistema ng lipunan, maraming salik ang higit na nakakaapekto at nakaambag sa paglinang ng kakayahan ng mga bagong botante sa iba't ibang larang ng pagtuklas maging sa karanasan ng mga kandidato. Mga istilo, pamamaraan, metodo at iba pang teknikal na suporta na naglalayon ng pag-unlad ng kakayahang ng dimensyunal na pagpili sa isang kandidatong dapat niyang ihalal. Kung higit na susuriin ang tanging layunin ng politika ay lubusang nakatuon sa isang pagboto ng mga botante, hindi gaanong binibigyan ang pagkakakilanlan ng isang botante sa isang maparaan nitong pagkakakilanlan bilang isang botante na nagtatanging mapanuri ang pagpili ng kandidato.

Ayon nga sa pag-aaral ng mga eksperto, ito ay nagbibigay ng pagtangin sa kakayahan ng mga bagong botante at ang mga datihang botante sa larangang sosyal at panlipunan. Inilahad sa pag-aaral na ito ang natatanging kahinaan at kalakasan ng mga bagong botante at datihang botante sa lipunan. Ang kanilang gampanin at pagkakakilanlan. Kung susuriin ang mag nilalaman ng mga programa ng eleksiyon, alinsunod nga sa karapatan ng bawat botante nakatuon lamang ito kung paano tatanggapin ng walang pakundangang pag-iimbot ang kakayahan ng mga bagong botante. Hindi pa lubusang nabibilang sa isang natatanging oryentasyon bilang isang botante. Ang mga nabanggit na mga kadahilanan ang nag-udyok sa mananaliksik upang isagawa ang pag-aaral tungkol sa paraan ng pagboto ng mga kabataan sa larangan ng pagpili at pagboboto.

\subsection{Paglalahad ng suliranin}

Ang pag-aaral na ito na matukoy ang pulso ng kabataan sa darating na Halalan 2022 sa Veritas College of Irosin.

Ano - ano ang impak ng pagkakaroon ng halalan taong 2022? 
$>\quad$ Ano - ano ang mga paghahanda ng mga mamamayan sa darating na halalan 2022?

$>\quad$ Ano ang rekomendasyon ng pag- aaral batay sa resulta at pag- aanalisa ng mga datos?

\section{Pamamaraang ginamit}

Ginamit ang deskriptib-analisis na disenyo ng pananaliksik. Ang mga naging kalahok ay binubuo ng 76 mula sa 8 seksiyon ng mag-aaral ng BSBA sa Veritas College of Irosin. Gumamit ng talatanungan para malaman ang mga istratehiyang ginamit sa pagsusuri ng mga kabataan sa larangan ng pgboboto. Nagsagawa ng online interview sa mga kalahok sa pamamagitan ng paghingi ng pahintulot at pagpaliwanag sa isinagawang pananaliksik. Ginamit ang frequency count at pagraranggo upang maanalisa ang datos sa impak, salik na pagpili ng mga kabataan sa pagboto. Purposive sampling ang ginamit ng mananaliksik sa pagkuha ng 25 na BSBA na mag-aaral na kalahok bilang target ng pananaliksik. Inalam na muna ng mananaliksik ang mga seksiyon na mayroong bagong botante na nag-aaral sa Veritas College of Irosin. May iilan na ipinahayag nila sa kanilang saloobin na pagboto ngunit may iilan na nilihim ang kanilang intensiyon sa pagboto.

Gumamit ng random sampling sa pagpili ng mga kalahok sa bawat mag-aaral ng Veritas College of Irosin ayon lamang sa mga target na kalahok na nabibilang sa komunidad ng mga botante. Ang sampling at pagtatalaga ng mga kalahok sa pananaliksik ay bahagi ng proseso ng pananaliksik na kritikal sa tagumpay at katumpakan ng pananaliksik (Hu et al., 2012). Ito ay ginamit para sa mga mag-aaral ng BSBA. Ang mga nakalap na datos ay inalisa, sinuri at binigyan ng interpretasyon gamit ang pagbilang, at pagraranggo. Kinuha rin ng mananaliksik ang saklaw (range) na pagpili ng kabataan na mag-aaral ng BSBA sa Veritas College of Irosin.

\section{Mga natuklasan}

\subsection{Mga Istratehiyang ginamit ng mga kabataan ng Irosanon}

Natuklasan na ang istratehiyang ginagamit sa pagsusuri ng kabataan sa larangan ng pagbotoay reversal na istratehiya na mayroong 23 na kalahokna sumagot na ang pipiliin nilang kandidato ay may magandang nakaraan at mayroon mabuting intensiyon sa bayan. Pangalawa sa ranggo ang Election campaign na sinagutan at sinundan ng Cultured voting na may kalahok na 21 na sumagot. Ang mga tuklas o imbentong paraan ng pagsusuri ay mahalaga upang higit na mabilis, magaan at epektibo ang pagpili. Kaya't kailangan magkaroon ng malawak na kaalaman ang mga kabataan sa taong kaniyang iboboto upang may kakayahan siyang bigyan ng bagong bihis ang pamahalaan sa ganun ay mabuksan niya ang mas mapanuring kaisipan ng mga kabataan sa pagkatuto sa eleksiyon. Nabanggit nga sa pag-aaral na pangunahing tungkulin ng mga botante ang paghuhusga at pagsusuri ng kandidato. Ito ay upang magbigay ng impormasyon at maimulat sa kawilihan ng isang botante sa larangan ng pagboto. Ang mabuting pangangasiwa ng botante ay pagkakaroon ng episyenteng aksiyon at mga pamamahala ng pamahalaan na higit na magdudulot sa kaalaman ng botante na pakikinabangan ng kabataan.

\section{Talahanayan 1}

Istratehiyang ginagamit sa pagsusuri ng kabataan sa larangan ng pagboto

\begin{tabular}{lccccc}
\hline \multicolumn{1}{c}{ Halalan } & $30-18$ & $30-19$ & $30-20$ & Kabuuan & Ranggo \\
\hline Election campaign & 10 & 8 & 4 & 22 & 2 \\
Candidate platform & 7 & 5 & 3 & 15 & 5 \\
Political ads & 9 & 2 & 5 & 16 & 4 \\
Cultured voting & 9 & 10 & 2 & 21 & 3 \\
Reversal na pagpili & 11 & 5 & 7 & 23 & 1 \\
\hline
\end{tabular}

Samantala, ang istratehiyang ginagamit sa pagpili ng mga kandidatong kakayahang mapaunlad ang bansa sa larangan ng pagboto na sinagutan ng 32 na kalahok na may mabuting intensiyon sa pagpili ng ibobotong kandidato. Pangalawang istratehiya sa pagboto ng kabataan ang Brand awareness na may kalahok na 30 ang sumagot sa nagsabing mas mabuting maging mapanuri sa kandidatong iboboto. Ang istratehiya sa pagpipili ng 
Ranoco, M. Z. B., Doritan, J. L., Fuller, R. M., Pamplona, M., \& Gelilio, E.

kandidato na nagsasabing ang pagsusuring ito magiging mabuting huwaran. Upang maiangat ang mga kabataan botante na may maraming pangangailangan. Pinatutunayan ng pag-aaral na ito na ang mga kabataan ay natututo upang makuha ang tanging layunin ng mataas na antas ng pagsusuri, sapagkat ang kabataan ay may mataas na karunungan sa pagpili sa paraan ng pag-aanalisa ng konsepto sa pagboto.

\section{Talahanayan 2}

Istratehiyang ginagamit sa pagsusuri ng kabataan sa larangan ng pagboto

\begin{tabular}{lccccc}
\hline \multicolumn{1}{c}{ Eleksiyon } & $30-18$ & $30-19$ & $30-20$ & Kabuuan & Ranggo \\
\hline Good or bad campaign & 12 & 5 & 8 & 25 & 3 \\
Inverse platform & 5 & 3 & 7 & 15 & 5 \\
Candidate platform & 16 & 9 & 7 & 32 & 1 \\
Brand awareness & 13 & 13 & 4 & 30 & 2 \\
Political ads & 9 & 5 & 9 & 23 & 4 \\
\hline
\end{tabular}

\subsection{Mga Salik na nakakaapekto sa pagsusuri ng kabataan sa larangan ng pagboboto}

Ang mga salik na nakakaapekto sa pagsusuri ng kabataan sa larangan ng pagboboto ay ang kawalan ng inobatibong pamamaraan ng pagsusuri na may 21 na kalahok ang sumagot na hindi epektibo ang mga pamamaraan na ipinapatupad ng pamahalaan. Pangalawang salik na hindi sapat ang hakbang na ipinapatupad ng pamahalaan. Pinatunayan sa pag-aaral ng eksperto, bagaman ang kabataan ay dumaan sa pagiging mapili at hindi pa kongkreto ang kanilang desisyon hindi pa rin maalis na may pamamaraang hindi pa rin dapat gawin sa pagboto. Kinakailangan na ang mga botante ay nabibigyan ng mga bagong- tuklas upang ipakilala rin sa iba pang botante ang tuklas. Sa paggamit ng masuring paraan sa pagboto, magiging epektibo lamang ito kung nauunawaan ng botante ang pangunahing panukala at mga batas kung saan at paano maiaangkop ang isang istratehiya sa pagboto. Mahalaga ayon sa eksperto na magkaroon ng sapat na kaalaman sa pagboboto maging ang mga bagong tuklas na pamamaraan at istratehiya sa pagboto.

\section{Talahanayan 3}

Salik na nakakaapekto sa pagsusuri ng kabataan sa larangan ng pagboboto

\begin{tabular}{|c|c|c|c|c|c|}
\hline Halalan & $30-18$ & $30-19$ & $30-20$ & Kabuuan & Ranggo \\
\hline $\begin{array}{l}\text { Hindi sapat ang hakbang na ipinapatupad ng } \\
\text { pamahalaan }\end{array}$ & 9 & 9 & 2 & 20 & 2 \\
\hline Kakulangan sa tulong ng gobyerno & 8 & 7 & 4 & 19 & 3 \\
\hline $\begin{array}{l}\text { Hindi malinaw ang pagpapakilala ng } \\
\text { kandidato }\end{array}$ & 3 & 5 & 3 & 13 & 5 \\
\hline $\begin{array}{l}\text { Hindi sapat ang oras upang makilala ang } \\
\text { isang kandidato }\end{array}$ & 5 & 7 & 3 & 15 & 4 \\
\hline Kawalan ng inobatibong pamamaraan & 7 & 5 & 9 & 21 & 1 \\
\hline
\end{tabular}

\subsection{Impak ng pagsusuri ng kabataan sa mga datihang botante}

Ang positibong impak ng pagsusuri ng kabataan ay mabisa an pamamaraan ng pagboto sa paraang tama at kaaya- aya na sinagutan ng 46 na kalahok. Pangalawa ang mapaunlad ang kakayahan ng kabataan sa larangan ng pagboto na may 45 na kalahok at sinundan ng gumagawa ng inobatibong pamamaraan ng pagboto ng kabataan na sinagutan ng 44 na kalahok. Binanggit s pag- aaral, noong unang bahagi ng 2019, inaprubahan ng lungsod ang kasunduan ng Departamento ng mga Eleksyon at Dominion Voting System sa pag- upa at paggamit ng Sistema ng pagbotong Dominion upang magsagawa ng mga eleksiyon sa San Francisco. Nagsimulang gamitin ng mga bagong botante ng San Francisco ang sistema ng pagbotosa Nobyembre 5, 2019 pinagsamang pangmunisipal na eleksyon. Pinatutuhanan nito ang likas na ang mga baguhang botante na may kakayahang magbigay ng marangal at tapat na eleksiyon. 


\section{Talahanayan 4}

Positibong Impak ng pagboto ng kabataan

\begin{tabular}{lccccc}
\hline \multicolumn{1}{c}{ Positibo } & $\begin{array}{c}\text { First year } \\
\text { college }\end{array}$ & $\begin{array}{c}\text { Second year } \\
\text { college }\end{array}$ & $\begin{array}{c}\text { Third year } \\
\text { college }\end{array}$ & Kabuuan & Ranggo \\
\hline $\begin{array}{l}\text { Inspirasyon ng mga kabataan sa patuloy na } \\
\text { daloy ng eleksiyon }\end{array}$ & 13 & 17 & 12 & 42 & 4 \\
$\begin{array}{l}\text { Gumagawa ng paraan upang mapagaan ang } \\
\text { halalan }\end{array}$ & 9 & 15 & 16 & 40 & 5 \\
$\begin{array}{l}\text { Gumagawa ng mga inobatibong pamamaraan ng } \\
\text { pagboto ng kabataan }\end{array}$ & 18 & 14 & 12 & 44 & 3 \\
$\begin{array}{l}\text { Mapaunlad ang kakayahan ng kabataan sa } \\
\text { larangan ng pagboto }\end{array}$ & 19 & 15 & 11 & 45 & 2 \\
$\begin{array}{l}\text { Mabisa ang pamamaraan ng pagboto sa paraang } \\
\text { tama at kaaya-aya }\end{array}$ & 15 & 19 & 12 & 46 & 1 \\
\hline
\end{tabular}

\subsection{Interbensyon batay sa resultang pag-aaral}

Isang panukalang Republic Act No. 8189 ay kilala bilang "The Voter's Registration Act of 1996" upang maging batayan ng kabataan na ang batas na ito ay nagbibigay ay pangkalahatang karapatan ng magparehistro bilang isang botante. Maaaring pagbatayan ang pananaliksik na ito ng mga susunod na mananaliksik upang higit na palawigin ang pagsusuri ng kabataan ayon sa tunguhin ng susunod na mananaliksik.

\section{Kongklusyon}

Batay sa natuklasan, nabuo ang sumusunod na kongklusyon:

$>\quad$ Iba't ibang istratehiya ang ginamit sa pagsusuri ng paraan sa pagboto na ginagamit ng mga kabataan sa pagboto sapagkat iba-iba ang pamamaraan ginagamit sa pagboboto ng botante sa magkaibang larangan ng pagboboto.

$>\quad$ May mga salik na nakakaapekto sa pagboboto ng mga botante sa larangan ng pagboto.

$>\quad$ May positibo at negatibo impak ang pagboboto ng isang botante sa larangan ng pagboto.

\subsection{Rekomendasyon}

Batay sa mga resulta at kongklusyon ng pag-aaral na ito, ang mga sumusunod na mga rekomendasyon ay nabuo:

> Bigyan ng pansin ang mga botanteng bumubuto sa paraang mabuti at bigyan ng malayang karapatan ang natatanging kakayahan ng botante na bumuto at magtuklas ng mga bagong pamamaraan at inobatibong pagpili sa larangan ng pagboto.

$>\quad$ Magkaroon ng mas konkretong pagpapahayag sa kanilang saloobin na naayon sa kanilang pananaw at kung paano maisasatitik ang mga inobatibong pamamaraan ng pagpili sa larangan ng pagboto.

$>\quad$ Mas palawakin ang pag- unawa at paghuhusga sa kandidatong dapat nating iboto upang higit na makilala ang tunay nilang pagkakakilanlan maging tamang pakikipag- ugnayan sa mga kandidatong dapat nating ihalal.

$>\quad$ Kung maaari ay gamitin ang inyong karapatan bilang botante upang maging batayan sa pagboboto ay ang hangarin na mapabuti at maisaayos ang pamumuno ng ating pamahalaan.

$>\quad$ Maaaring pagbatayan ang pananaliksik na ito ng mga susunod na mananaliksik upang higit na palawigin ang pagsusuri sa mga pamamaraan sa pagboto ng kabataan ayon sa tunguhin ng susunod na 
Ranoco, M. Z. B., Doritan, J. L., Fuller, R. M., Pamplona, M., \& Gelilio, E.

mananaliksik.

\section{Talasanggunian}

Antunes, R. (2019). Theoretical models of voting behavior. Exedra, 4, 145-170.

Augusto, D. C., \& da Silva, M. (2016). The formation of voter's from family and educational. European Scientific Journal, 1, 455-463.

Branco, R. U. I., \& Cardoso, D. (2020). Coalitional politics and labour market reforms. Journal of Social Policy. https://doi.org/10.1017/S0047279420000653

French Presidential Election. (2017). Retrieved from

https://en.wikipedia.org/wiki/2022_French_presidential_election

Hu, Y. L., Ching, G. S., \& Chao, P.-C. (2012). Taiwan student engagement model: Conceptual framework and overview of psychometric properties. International Journal of Research Studies in Education, 1(1), 69-90. https://doi.org/10.5861/ijrse.2012.v1i1.19

Jorge, R. D. S. (1995). Voting behavior. Retrieved from https://en.m.wikipedia.org/wiki/votingbehavior.org

Noval, A. T. (2020) Cebu Technological University, Cebu, Philippines. Retrieved from https://freesearch.inprivatesearch.com/search

Ramos, R., \& Lopes, F. F. (1991). How did they become voters? Kluwer Law International. 